\title{
Morphology and amplitude values of the electrocardiogram of Spanish-bred horses of different ages in the Dubois leads system
}

\author{
Ignacio AyAla ${ }^{\text {a* }}$, Cándido Gutierrez-PANIZO ${ }^{\mathrm{a}}$, \\ José Luis Benedito ${ }^{\mathrm{b}}$, Felipe PrIeto $^{\mathrm{c}}$, Ana Montes ${ }^{\mathrm{a}}$ \\ ${ }^{\text {a }}$ Departamento de Patología Animal (Medicina Veterinaria), Facultad de Veterinaria, \\ Universidad de Murcia, Campus de Espinardo, 30100 Murcia, Spain \\ ${ }^{\mathrm{b}}$ Departamento de Patología Animal, Facultad de Veterinaria de Lugo, \\ Universidad de Santiago de Compostela, Spain \\ ${ }^{c}$ Departamento de Patología Animal, Facultad de Veterinaria, Universidad de León, Spain
}

(Received 18 October 1999; accepted 10 February 2000)

\begin{abstract}
The aim of this work was to record the modifications of the form and amplitude of the electrocardiographic tracings during growth using the Dubois system and to study its sensibility to these physiological changes. This work was carried out on 179 healthy, young and adult Spanish-bred horses (98 females and 81 males). One electrocardiogram (ECG) was obtained from each horse using the Dubois leads system. The bifid shape deflection of the $\mathrm{P}$ wave was generally more frequent than the simple one in animals at 4 months of age or older. Amplitudes of the $\mathrm{P}_{2}$ component and of the simple positive wave presented significant differences $(p<0.01)$ between the age groups studied: animals up to 3 months in age and older than 2 years of age (highest amplitudes), and the rest of the animals (lowest amplitudes). Significant variations $(p<0.05)$ were found for the QS amplitude between animals of 1 month of age, and all the other groups. The multiple range analysis did not define a clear distribution of age groups for the amplitude of the T wave. It may therefore be concluded, that in the Spanish-bred horse up to 1 month of age, the form and amplitude of the QRS complex in the Dubois leads system differ from those of older animals. Thus, this study shows the sensibility of the Dubois leads system for detecting the electrocardiographic changes related to the growing process in the Spanish-bred horse. In addition, it provides standard values of electrocardiographic parameters in the Spanish-bred horse at different stages of growth.
\end{abstract}

Dubois leads / electrocardiogram / horse / Spanish-bred

* Correspondence and reprints

Tel.: (34) 968 367070; fax: (34) 968 364147; e-mail: iayape@fcu.um.es 
Résumé - Morphologie et valeurs d'amplitude de l'électrocardiogramme chez les chevaux de race espagnole de différents âges en utilisant le système de dérivations de Dubois. Le but de ce travail est d'enregistrer les modifications de la forme et de l'amplitude des tracés électrocardiographiques au cours de la croissance, en utilisant le système de Dubois. Nous tentons de vérifier la sensibilité du système des dérivations de Dubois pour détecter des changements physiologiques. L'étude a été réalisée sur 179 chevaux de race espagnole jeunes et adultes (98 femelles et 81 mâles) exempts d'anomalie. Un électrocardiogramme a été réalisé chez chaque cheval, en employant le système des dérivations de Dubois. La forme bifide de l'onde $\mathrm{P}$ a été généralement plus fréquente que la forme simple chez les chevaux âgés de 4 mois ou plus. Les amplitudes de la partie $\mathrm{P}_{2}$ et de l'onde $\mathrm{P}$ simple positive ont présenté des différences significatives $(p<0,01)$ parmi les groupes : les animaux d'âge inférieur à 3 mois et ceux âgés de plus de 2 ans (les plus grandes amplitudes) et le reste des animaux (les plus basses amplitudes). Des différences significatives $(p<0,05)$ de l'amplitude d'onde QS ont été montrées entre les animaux d'1 mois et les autres groupes d'âge. L'analyse statistique n'a pas révélé une distribution des groupes d'âge pour l'amplitude d'onde T. En conséquence, on peut conclure, que chez le cheval de race espagnole, la forme et l'amplitude du complexe QRS dans le système des dérivations de Dubois chez les animaux âgés de moins d'1 mois sont différentes de celles des animaux plus âgés. Ce travail montre ainsi la sensibilité du système des dérivations de Dubois pour détecter les changements électrocardiographiques associés à la croissance chez le cheval de race espagnole. De plus, il fournit des valeurs électrocardiographiques qui peuvent être utilisées comme référence chez le cheval de race espagnole en rapport avec les différentes étapes de la croissance.

dérivations de Dubois / électrocardiogramme / cheval espagnol

\section{INTRODUCTION}

Many different lead systems for recording electrocardiograms in the horse have been studied by several authors $[2,4,7,11$, $12,13]$. Some authors consider the diagnostic value of Einthoven leads in the horse as not very great because the amplitudes of the electrocardiograms obtained with this technique show a wide variation: Dubois [4], Hilwig [10, 11], Holmes and Else [13], Lescure [16].

In France, the Dubois leads system has been used as an alternative method $[4,16]$. For these authors, the Einthoven technique is not adequate in the horse because of the influence of the position of the limbs on the ECG tracings and also the inadequacy of the leads position on the horse in relation to the position of the heart in the thorax.

The aim of this work was to study the modifications of the form and amplitude of the electrocardiographic tracings during growth, using the Dubois system, in order to verify its sensibility in detecting the elec- trocardiographic changes related to the growing process. In fact, using the Einthoven leads, changes in form and amplitude of the QRS complex and the direction of its main vector have been related to the changes in size and position of the heart in the thorax during growth, as a result of physical maturation [1,3]. We verified the sensibility of the Dubois lead system to these physiological changes as an indirect method in determining its diagnostic value for pathological alterations.

In addition, limited information exists about electrocardiographic changes in the horse during growth $[17,18]$. However, only certain breeds, mainly Thoroughbreds were used in these studies. Electrocardiographic changes during growth have not been completely studied in the Spanish-bred horse. Some authors $[10,15]$ have emphasized the importance of obtaining values for every specific breed. Thus, standard values of electrocardiographic parameters in the Spanishbred horse at different stages of growth are needed. This investigation was undertaken to determine these values. 


\section{MATERIALS AND METHODS}

This study was carried out on 179 healthy, young and adult Spanish-bred horses (98 females and 81 males). These horses were reared under ordinary management on the military stud of Jerez de la Frontera (Cádiz, Spain). The horses were between one month and 17 years of age. Table I shows the distribution of these age groups.

One ECG was obtained from each horse using a portable Cardioline ETA 340 3-channel electrocardiograph, with a paper speed of $25 \mathrm{~mm} \cdot \mathrm{sec}^{-1}$ and a sensitivity of $10 \mathrm{~mm} \cdot \mathrm{mV}^{-1}$. The Dubois leads (I, II, III) were used [4]. Alligator clips fixed to the electrocardiographic leads were attached directly to the skin after vigorous application of an electrode paste. The electrodes were placed on the shoulders (middle point between the withers and the point of the shoulder) and on the xiphoid process of the sternum $[4,16]$. All recordings were taken with the horse standing in the stable. The forelimbs were kept parallel to each other and perpendicular to the long axis of the body. The animals were insulated from the ground by means of a rubber mat. Before each recording, we waited a short period for the horses to calm down.

Measurements of the wave amplitudes were made manually on three cardiac cycles of lead II, and only in those registers in which outlines were acceptable for their measurement. The values were calculated from the mean of these measurements. Mean and standard error of mean were calculated for each ECG value. The mean electrical axis of the QRS complex on the horizontal plane, as derived from the ventral aspect of the animal, was calculated from the algebraic sum of the deflections in the QRS complexes. An analysis of variance was made to examine the effect of sex for each age group. A similar analysis was made to examine changes in the values obtained among age groups. A multiple range analysis was carried out to determine whether or
Table I. Distribution of the 179 horses in the different groups according to age and sex. N refers to the total number of individuals in each group.

\begin{tabular}{lcccc}
\hline Groups & Months & Males & Females & $\mathrm{N}$ \\
\hline $\mathbf{1}$ & 1 & 5 & 9 & 14 \\
$\mathbf{2}$ & 2 & 4 & 4 & 8 \\
$\mathbf{3}$ & 3 & 4 & 2 & 6 \\
$\mathbf{4}$ & 4 & 4 & 2 & 6 \\
$\mathbf{5}$ & 5 & 1 & 4 & 5 \\
$\mathbf{6}$ & 6 & 4 & 2 & 6 \\
$\mathbf{7}$ & 7 & 3 & 4 & 7 \\
$\mathbf{8}$ & 8 & 6 & 1 & 7 \\
$\mathbf{9}$ & 9 & 0 & 10 & 10 \\
$\mathbf{1 0}$ & 10 & 1 & 4 & 5 \\
$\mathbf{1 1}$ & 11 & 0 & 5 & 5 \\
$\mathbf{1 2}$ & $12-24$ & 12 & 14 & 26 \\
$\mathbf{1 3}$ & $25-36$ & 12 & 16 & 28 \\
$\mathbf{1 4}$ & $37-48$ & 14 & 12 & 26 \\
$\mathbf{1 5}$ & $>48^{\mathrm{a}}$ & 11 & 9 & 20 \\
\hline
\end{tabular}

a Ages ranged from 4 to 17 years with a mean value of 7 years.

not changes were significant at any particular time. It was considered that $p<0.05$ was significant.

\section{RESULTS}

The electrocardiograms recorded showed $\mathrm{P}$ waves of different configurations. Bifid $(+/+)$, simple positive and biphasic $(-/+)$ shapes were observed in the various age groups. The bifid shape deflection of the $\mathrm{P}$ wave was generally more frequent than the simple one in animals over 4 months of age (Tab. II). The biphasic shape was observed in several age groups. The biphasic deflections were always of the negative / positive type.

The first component of the bifid P-waves $\left(\mathrm{P}_{1}\right)$ did not vary significantly with an advance in age or with sex, showing a mean value of $0.147 \mathrm{mV}$. The amplitude of the $\mathrm{P}_{2}$ (second component of the bifid P-waves) presented significant differences between the age groups studied (Tab. III). The 
Table II. Percentages of the several forms of P-waves, QRS complex and T-waves (lead II).

\begin{tabular}{|c|c|c|c|c|c|c|c|c|c|c|}
\hline \multirow[b]{2}{*}{ Groups } & \multicolumn{3}{|c|}{ P-Waves } & \multicolumn{4}{|c|}{ QRS complex } & \multicolumn{3}{|c|}{ T-Waves } \\
\hline & $\mathrm{P}+$ & $\mathrm{P}+/+$ & P $-/+$ & $\mathrm{rS}$ & QS & RS & others & $\mathrm{T}-$ & $\mathrm{T}+$ & $\mathrm{T}-/+$ \\
\hline 1 & 55.6 & 44.4 & - & 55.5 & 27.8 & - & 16.7 & 16.7 & 55.5 & 27.8 \\
\hline 2 & 50 & 50 & - & 40 & - & 30 & 30 & 50 & 20 & 30 \\
\hline 3 & 60 & 40 & - & 90 & 10 & - & - & 30 & 10 & 60 \\
\hline 4 & 30 & 60 & 10 & 100 & - & - & - & 20 & 10 & 70 \\
\hline 5 & 41.7 & 58.3 & - & 83.3 & - & 16.7 & - & 50 & 8.3 & 41.7 \\
\hline 6 & 16.7 & 75 & 8.3 & 66.7 & 25 & 8.3 & - & 25 & 8.3 & 66.7 \\
\hline 7 & 20 & 70 & 10 & 80 & 10 & 10 & - & 10 & - & 90 \\
\hline 8 & 5.6 & 88.9 & 5.5 & 66.7 & 22.2 & 11.1 & - & 22.2 & - & 77.8 \\
\hline 9 & 9.5 & 90.5 & - & 61.9 & 23.8 & 14.3 & - & 14.3 & - & 85.7 \\
\hline 10 & 18.2 & 63.6 & 18.2 & 90.9 & 9.1 & - & - & 27.3 & - & 72.7 \\
\hline 11 & - & 100 & - & 72.7 & 18.2 & 9.1 & - & 18.2 & - & 81.8 \\
\hline 12 & 19.2 & 80.8 & - & 65.4 & 23.1 & 11.5 & - & 23.1 & - & 76.9 \\
\hline 13 & 14.3 & 82.1 & 3.6 & 67.8 & 21.5 & 10.7 & - & 3.6 & 3.6 & 92.8 \\
\hline 14 & 27.9 & 66.3 & 5.8 & 73.1 & 19.2 & 7.7 & - & 4.5 & 20.2 & 75.3 \\
\hline 15 & 25 & 70 & 5 & 60 & 25 & 15 & - & 5 & 45 & 50 \\
\hline
\end{tabular}

Table III. Mean (standard error of mean) of P-Wave amplitudes in mV (lead II).

\begin{tabular}{|c|c|c|c|c|c|}
\hline \multirow[b]{2}{*}{ Groups } & \multicolumn{2}{|c|}{ Bifid P } & \multirow{2}{*}{$\frac{\text { Simple } \mathrm{P}}{\mathrm{P}+}$} & \multicolumn{2}{|c|}{ Biphasic P } \\
\hline & $\mathrm{P} 1$ & $\mathrm{P} 2$ & & P - & $\mathrm{P}+$ \\
\hline 1 & $0.15(0.02)$ & $0.28(0.01)$ & $0.33(0.02)$ & - & - \\
\hline 2 & $0.18(0.03)$ & $0.24(0.02)$ & $0.29(0.02)$ & - & - \\
\hline 3 & $0.13(0.02)$ & $0.26(0.03)$ & $0.22(0.03)$ & - & - \\
\hline 4 & $0.14(0.01)$ & $0.20(0.01)$ & $0.25(0.02)$ & $0.10(0)$ & $0.20(0)$ \\
\hline 5 & $0.13(0.01)$ & $0.21(0.01)$ & $0.25(0.02)$ & - & - \\
\hline 6 & $0.13(0.01)$ & $0.22(0.01)$ & $0.30(0)$ & $0.05(0)$ & $0.25(0)$ \\
\hline 7 & $0.15(0.01)$ & $0.24(0.01)$ & $0.26(0.03)$ & - & - \\
\hline 8 & $0.12(0.01)$ & $0.22(0.01)$ & $0.30(0)$ & $0.05(0)$ & $0.22(0)$ \\
\hline 9 & $0.14(0.01)$ & $0.21(0.01)$ & $0.26(0.05)$ & - & - \\
\hline 10 & $0.17(0.01)$ & $0.25(0.02)$ & $0.31(0.01)$ & $0.07(0.02)$ & $0.10(0)$ \\
\hline 11 & $0.13(0.01)$ & $0.20(0.02)$ & - & - & - \\
\hline 12 & $0.15(0.01)$ & $0.24(0.01)$ & $0.30(0)$ & - & - \\
\hline 13 & $0.16(0.01)$ & $0.28(0.01)$ & $0.28(0.03)$ & $0.05(0)$ & $0.21(0)$ \\
\hline 14 & $0.15(0.01)$ & $0.26(0.02)$ & $0.27(0.02)$ & $0.10(0)$ & $0.20(0)$ \\
\hline 15 & $0.12(0.01)$ & $0.23(0.01)$ & $0.32(0.04)$ & - & - \\
\hline$P$ & n. s. & 0.006 & 0.005 & - & - \\
\hline
\end{tabular}

multiple range analysis showed the highest $\mathrm{P}_{2}$ amplitudes in animals up to 3 months old and over 3 years of age (Tab. III). Mean values of $\mathrm{P}_{2}$ amplitudes were significantly higher $(p<0.05)$ in males $(0.260 \mathrm{mV})$ than in females $(0.229 \mathrm{mV})$.
The changes of the simple positive $\mathrm{P}$ amplitude with growth were similar to the changes of $\mathrm{P}_{2}$ (higher $\mathrm{P}$ amplitudes were found in animals up to 2 months and over 2 years of age). 
The biphasic deflections of horses in the different age groups showed mean values between -0.05 and $-0.10 \mathrm{mV}$ for the first component (negative) and between 0.10 and $0.25 \mathrm{mV}$ for the second component (positive).

During growth, the QRS complex of the equine ECG appears in several forms in the Dubois system: rS, QS and RS configurations were the most frequent (Tab. II; Figs. 1 and 2). These negative configurations were found in all the age groups.

The Q-wave was only found in certain groups with values between 0.05 and $0.13 \mathrm{mV}$. The QS configuration (a simple negative one) presented significant variations for the mean amplitude values between the different age groups (Tab. IV). The highest one was found in foals of 1 month of age. No significant differences were found for the amplitudes of the R-wave and $\mathrm{S}$-wave among the several age groups nor between sexes. The multiple range analysis defined the homogeneity of all the age groups, with a mean total value of $0.29 \mathrm{mV}$ for the R-wave and $-0.95 \mathrm{mV}$ for the S-wave.

The results of the analysis of the T-wave are shown in Tables II and V, where the various configurations are indicated. Several configurations of the T-wave were observed in the different age groups. The younger animals (1 month old) generally presented a positive shape. The biphasic (-/+) pattern became more frequent in the rest of the animals (with the exception of groups 2 and 5) (Tab. II).

No significant differences according to age were found for the amplitude values of the simple positive and negative T-waves. Significant differences were found for both negative and positive components of the biphasic $\mathrm{T}$-waves but the multiple range analysis did not define a clear distribution of age groups. However, the multiple range analysis showed a tendency towards higher amplitudes with older animals than with the younger ones.

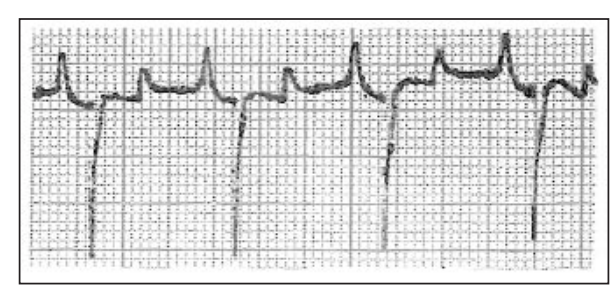

Figure 1. ECG tracing with lead II of group 1 (1-month-old animals): simple positive P, QRS complex -type QS- and positive T.

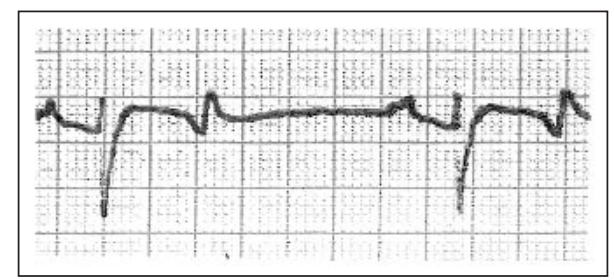

Figure 2. ECG tracing with lead II of group 15 (adults): bifid P, QRS complex -type rS- and biphasic $\mathrm{T}$.

\section{DISCUSSION}

The electrocardiograms recorded in Spanish-bred horses showed P waves with different configurations (bifid, simple and biphasic waves), which is in agreement with the results of several authors $[4,16]$. The bifid shape deflection of the $\mathrm{P}$ wave was generally more frequent than the simple one in animals at 4 months of age or older, probably due to the lower heart rate values in these animals. It shows a relationship between high heart rate and fusion of the two components of the bifid $\mathrm{P}$-wave $\left(\mathrm{P}_{1}\right.$ and $\mathrm{P}_{2}$ ) into only one, forming a simple positive shape. On the contrary, variations in the autonomic nervous system activity as seen with excitation or exercise appear to be responsible for changes in the $\mathrm{P}$ wave form $[6,8]$. Therefore, the increased frequency of the bifid morphology at 4 months of age or older could be due to a decrease in 
Table IV. Mean (standard error of mean) of QRS complex amplitudes in mV (lead II).

\begin{tabular}{lcccc}
\hline Groups & Q & QS & $\mathrm{R}$ & $\mathrm{S}$ \\
\hline 1 & $0.13(0.03)$ & $1.68(0.22)$ & $0.36(0.04)$ & $1.08(0.04)$ \\
2 & $0.10(0)$ & $0.80(0)$ & $0.42(0.06)$ & $0.81(0.09)$ \\
3 & - & $1(0)$ & $0.23(0.04)$ & $1(0.05)$ \\
4 & - & - & $0.32(0.05)$ & $0.86(0.05)$ \\
5 & - & - & $0.35(0.04)$ & $0.80(0.03)$ \\
6 & $0.05(0)$ & $1.15(0.12)$ & $0.20(0.06)$ & $0.96(0.06)$ \\
7 & - & $1.20(0)$ & $0.22(0.04)$ & $1.03(0.05)$ \\
8 & - & $0.85(0.18)$ & $0.23(0.03)$ & $0.93(0.04)$ \\
9 & - & $0.95(0.09)$ & $0.27(0.04)$ & $0.96(0.05)$ \\
10 & - & $1(0)$ & $0.20(0.03)$ & $1.01(0.11)$ \\
11 & - & $0.95(0.24)$ & $0.29(0.03)$ & $0.85(0.09)$ \\
12 & - & $1.13(0.08)$ & $0.30(0.04)$ & $0.97(0.05)$ \\
13 & - & $1.20(0.14)$ & $0.30(0.04)$ & $0.99(0.04)$ \\
14 & - & $0.99(0.05)$ & $0.31(0.03)$ & $0.94(0.05)$ \\
15 & - & $1.26(0.14)$ & $0.26(0.04)$ & $0.97(0.07)$ \\
$p$ & - & 0.04 & n. s. & n. s. \\
\hline
\end{tabular}

Table V. Mean (standard error of mean) of T-Wave amplitudes in mV (lead II).

\begin{tabular}{lcccc}
\hline & \multicolumn{2}{c}{ Biphasic $\mathrm{T}$} & \multicolumn{2}{c}{ Simple T } \\
\cline { 2 - 3 } Groups & $\mathrm{T}-$ & $\mathrm{T}+$ & $\mathrm{T}-$ & $\mathrm{T}+$ \\
\hline 1 & $0.10(0)$ & $0.16(0.02)$ & $0.41(0.07)$ & $0.41(0.04)$ \\
2 & $0.28(0.07)$ & $0.10(0)$ & $0.47(0.06)$ & $0.32(0.07)$ \\
3 & $0.24(0.03)$ & $0.15(0.01)$ & $0.40(0.05)$ & $0.25(0)$ \\
4 & $0.28(0.02)$ & $0.15(0.01)$ & $0.41(0.01)$ & $0.25(0)$ \\
5 & $0.31(0.05)$ & $0.10(0)$ & $0.65(0.07)$ & $0.35(0)$ \\
6 & $0.25(0.04)$ & $0.18(0.02)$ & $0.55(0.13)$ & - \\
7 & $0.26(0.03)$ & $0.19(0.02)$ & $0.40(0)$ & - \\
8 & $0.40(0.04)$ & $0.17(0.01)$ & $0.53(0.03)$ & - \\
9 & $0.34(0.03)$ & $0.17(0.01)$ & $0.53(0.03)$ & - \\
10 & $0.41(0.04)$ & $0.16(0.02)$ & $0.56(0.14)$ & - \\
11 & $0.31(0.03)$ & $0.13(0.03)$ & $0.40(0.10)$ & $0.50(0)$ \\
12 & $0.42(0.04)$ & $0.17(0.01)$ & $0.73(0.08)$ & $0.40(0.05)$ \\
13 & $0.37(0.02)$ & $0.24(0.01)$ & $0.90(0)$ & $0.52(0.08)$ \\
15 & $0.26(0.03)$ & $0.23(0.01)$ & $0.70(0)$ & - \\
$p$ & $0.24(0.03)$ & $0.24(0.03)$ & $0.40(0)$ & $\mathrm{n} . \mathrm{s}$. \\
\hline
\end{tabular}

heart rate with age and the influence of the vagal tone.

There was no significant difference in amplitude of $\mathrm{P}_{1}$ with increasing age. $\mathrm{P}_{1}$ showed values which were within the range of those obtained by Lescure [16] in adult animals.
The amplitudes of the $\mathrm{P}_{2}$ component and simple positive waves presented significant differences between the age groups studied. A multiple range analysis defined two separate groups: one comprising animals up to 3 months of age and older than 2 years of age (highest amplitudes), and another made up of the rest of the animals (lowest ampli- 
tudes). The highest values found in animals up to 3 months of age could be caused by stress during the electrocardiographic examinations, since the animals were young and not used to the experimental conditions [5]. On the contrary, the highest amplitudes of $\mathrm{P}_{2}$ and simple positive $P$ wave observed in animals over 2 years of age were probably caused by different factors. Deegen and Matthiesen [3] observed changes in the cardiac muscle: mass relationship in foals during the first year of life. Hanak [9] found a rotation of the electric cardiac axis up to the age of 13 to 15 months. Thus, morphologic changes of the heart, associated to growth, could be responsible for the higher values of amplitude in Spanish-bred horses over 2 years old.

The variability in the QRS morphology (percentages of the several forms of the QRS complex) found in this study (Tab. II) agrees with the results of other authors who used the Dubois leads $[4,16]$. All the groups of age presented predominantly negative shapes (rS, QS and RS), which were due to the situation of the electrodes on the animal used in the Dubois system.

Significant variations were observed for the QS amplitude between animals of 1 month of age and all the other groups. No significant difference was found for the amplitude of Q, R and S waves and the direction of the QRS vector on the horizontal plane among the several age groups nor between sexes. These findings differ from those obtained using the Einthoven leads system (significant differences for the amplitude of the Q wave) [1], but show the sensibility of the Dubois leads system in detecting the electrocardiographic changes related to the variations in size and position of the heart in the thorax during growth, as a result of physical maturation.

Differences in the T-wave were observed between the different age groups. The youngest animals ( 1 month old) generally had a positive T-wave. The rest of the animals frequently presented a biphasic pat- tern (-/+). Significant differences were found for both negative and positive components of the biphasic T-waves but the multiple range analysis did not define a clear distribution of age groups. These findings could be explained by the differences in the ventricular repolarisation process, which is affected by numerous factors. In fact, the T-wave, which is associated with the ventricular repolarisation, is the most variable waveform in the electrocardiogram. It seems likely that the repolarisation process in the ventricular myocardium may be affected by the duration of diastole and other factors (training, fear, vagal activity, etc.), which affect the length of the diastole including the effects of the autonomic nervous system and metabolic effects on the myocardial fibres influenced by coronary flow [14].

It may therefore be concluded, that in the Spanish-bred horse up to 1 month of age, the form and amplitude of the QRS complex in the Dubois leads system differ from those of older animals. The changes in form and amplitude of the QRS complex could be related to the changes in size and position of the heart in the thorax during growth, as a result of physical maturation. Thus, this study has shown the sensibility of the Dubois leads system for detecting the electrocardiographic changes related to the growing process in the Spanish-bred horse. In addition, it provides standard values of electrocardiographic parameters in the Spanish-bred horse at different stages of growth.

\section{ACKNOWLEDGMENTS}

We are grateful to the military veterinarians Dr. M. Vinuesa, Dr. R. Guijo and Dr. M. Manso and all the members of the Military Stud of Jerez de la Frontera, Cádiz, Spain, for their help.

\section{REFERENCES}

[1] Ayala I., Montes A., Benedito J.L., Castillo C., Hernández J., Gutierrez C., García-Partida P., Modifications of the Form and Amplitude of the 
Electrocardiographic QRS Complex During Growth in the Spanish-Bred Horse, J. Vet. Med. A. 45 (1998) 309-317.

[2] Benazet P., Bordet R., Brion A., Fontaine M., Sevestre J., Étude télémétrique de l'électrocardiogramme du cheval de sport, Rec. Méd. Vét. 140 (1964) 449-459.

[3] Deegen E., Matthiesen T., Untersuchungen zum EKG des Fohlens. II. Entwicklung des QRSKomplexes in den Standard-ExtremitätenAbleitungen innerhalb des ersten Lebensjahres, Zentrabl. Veterinaemed. A, 24 (1977) 799-816.

[4] Dubois M., Du choix des dérivations et d'une normalisation de l'électrocardiogramme chez quelques ongulés domestiques, Rec. Méd. Vét. 133 (1961) 425-448.

[5] Eckenfels A., Trieb G., The normal electrocardiogram of the conscious Beagle dog, Toxicol. Appl. Pharmacol. 47 (1979) 567-584.

[6] Fregin G.F., The equine electrocardiogram with standardized body and limb positions, Cornell Vet. 72 (1982) 304-324.

[7] Fregin G.F., Electrocardiography, Equine Pract. 1 (1985) 419-432.

[8] Grauerholz H., Beitrag zur Systematik der PWelle im EKG gesunder Pferde, Berl-Münch. Tierärzt. Wochenschr. 92 (1979) 349-352.

[9] Hanak J., Angle of the electrical cardiac axis and magnitude of the ventricular vector in Thoroughbred foals, Acta Vet. Brno 50 (1981) 207212 .
[10] Hilwig R.L., Applied electronics for veterinary medicine and animal physiology, Charles C. Thomas Publisher, Illinois (U.S.A.), 1976.

[11] Hilwig RW., Cardiac arrhythmias, in: Robinson, N.E. (Ed.), Current Therapy in Equine Medicine, 2nd ed., W.B. Saunders Company, Philadelphia (U.S.A), 1987, pp. 154-164.

[12] Holmes J.R, Darke P.G.G., Studies on the development of a new lead system for equine electrocardiography, Equine Vet. J. 2 (1970) 12-21.

[13] Holmes J.R., Else R.W., Further studies on a new lead for equine electrocardiography, Equine Vet. J. 4 (1972) 81-87.

[14] Holmes J.R., Rezakhani A., Observations on the T-wave of the Equine Electrocardiogram, Equine Vet. J. 7 (1975) 55-62.

[15] Illera J.C., Hamlin R.L., llera M., Unipolar thoracic electrocardiograms in which $\mathrm{P}$ waves of relative uniformity occur in male horses, Am. J. Vet. Res. 48 (1987) 1697-1699.

[16] Lescure F., Utilisation pratique de l'électrocardiogramme de Dubois chez le cheval de sport. 15 ans de recherche, Prat. Vét. Equine 88 (1976) 47-53.

[17] Matsui K., Amada A., Sawazaki T., Kano I., Changes in electrocardiographic parameters with growth in Thoroughbred horses and Shetland ponies, Bull. Equine Res. Institute 20 (1983) 7786.

[18] Tovar P., Escabias M.I., Santisteban R., Evolution of the ECG from Spanish bred foals during the post-natal stage, Res. Vet. Sci. 46 (1989) 358362. 